\title{
Comparative efficacy of chloroquine and pyrimethamine-sulfadoxine versus artemether and pyrimethamine-sulfadoxine in the treatment of uncomplicated falciparum malaria in children
}

\author{
Femmy Tambajong, MD; Tonny H Rampengan, MD
}

\begin{abstract}
Background Large amount of data show that chloroquine and pyrimethamine-sulfadoxine (PS) as standard drugs for falciparum malaria cause resistance; for that reason new drugs or combination drugs are urgently needed. Artemether is one of the new drugs. It has been studied extensively in China and Southeast Asia during the past 10 years. The effectiveness of this drug in clearing parasites has been thoroughly documented.

Objective The objective of this study was to investigate the efficacy of the combination of chloroquine and PS compared to artemether and PS in the treatment of uncomplicated falciparum malaria.

Methods We did a single-blind randomized study on 60 children with uncomplicated falciparum malaria. Thirty children were treated with chloroquine $(10 \mathrm{mg} / \mathrm{kg}$ for 2 days, then $5 \mathrm{mg} / \mathrm{kg}$ in the $3^{\text {rd }}$ day) and PS (pyrimethamine $1-1.5 \mathrm{mg} / \mathrm{kg}$ single dose on the $1^{\text {st }}$ day) and the other 30 children were treated with artemether ( $4 \mathrm{mg} / \mathrm{kg} /$ day for 3 days) and PS. All patients were admitted to hospital for at least 7 days.

Results Fever clearance time was significantly shorter in the group that received artemether and PS compared to that in the chloroquine-and-PS group (42 hours vs. 75 hours 50 minutes, $p<0.0001$ ). Parasite clearance time was significantly different between the group that received artemether and PS and the chloroquine-andPS group ( 2.5 days vs. 3.1 days, $p=0.04$ ). The cure rate in the chloroquine-and-PS group was $28 / 30$ and that of the artemetherand-PS group was 30/30. Nausea and vomiting were found in 1 patient treated with chloroquine and PS.

Conclusion The combined treatment of artemether and PS was well tolerated. No adverse reactions attributable to the treatment were noted [Paediatr Indones 2004;44:228-233].
\end{abstract}

Keywords: chloroquine, pyrimethamine-sulfadoxine, artemether, fever clearance time, parasite clearance time, falciparum malaria

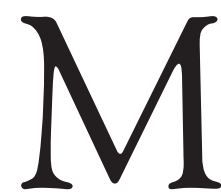

any efforts have been done to reduce the morbidity rate of falciparum malaria. Chloroquine and pyrimethamine-sulphadoxine (PS) until now are still the first line therapy for falciparum malaria in the world, including in Indonesia. ${ }^{1}$ The rapid emergence of resistance against first line drugs had been reported in Indonesia., ${ }^{2,3}$ It is likely to have a striking impact on childhood mortality in many regions where no obvious replacement for first line drugs is available.

Combination therapy against highly drug-resistant infectious diseases has been accepted worldwide. ${ }^{4}$ Artemether is a derivative of qinghaosu, which is an extract of the plant Artemesia annua.L. ${ }^{5}$ The action of artemether is at the erythrocytic stage of the parasite life cycle. The mechanism of action remains uncertain, but it is thought to cause free-radical damage to parasite membrane systems., ${ }^{5,6}$ Artemether stops parasite development rapidly, thus, prevents subsequent cytoadherence and rosetting. In areas of high

From the Department of Child Health, Medical School, Sam Ratulangie University, Manado, Indonesia.

Reprint requests to: Femmy Tambajong, MD; Department of Child Health, Medical School, Sam Ratulangi University, Central General Hospital of Manado, PO Box 1066 Manado. 
Femmy Tambajong et al: Artemether and pyrimethamine sulfadoxine in falciparum malaria treatment

drug resistance, the combination of first drug and artemisin derivatives (artesunat, artemether) has shown to be fully effective. ${ }^{7-9}$ The currently recommended regimens are artesunat or artemether $4 \mathrm{mg} /$ $\mathrm{kg}$ once a day for 3 days, plus mefloquine or PS. ${ }^{6}$ Previous studies have been done in adults with those regimens but there has been no detailed prospective evaluation of qinghaosu or its related compounds in children with malaria. ${ }^{10}$ The objective of this study was to evaluate the efficacy and safety of the combination of chloroquine and PS compared with artemether and PS in the treatment of uncomplicated falciparum malaria in children.

\section{Methods}

\section{Study site}

The study was conducted during the period of 7 months between March and September 2002 at the Manado Central General Hospital (MCGH), which is the main pediatric referral hospital in North Sulawesi. This area is considered to be endemic for $P$. falciparum with year-round transmission.

\section{Study design}

This was a single-blind randomized study on 60 children with uncomplicated falciparum malaria. Sample size was calculated to be 30 children in each study group (significance level $=5 \%$, power $=80 \%$ ). ${ }^{11}$ Children were included if they were between the ages of 6 months and 13 years, had symptoms compatible with acute falciparum malaria (with fever or a history of fever during the present illness for at least 48 hours), had positive blood film for $P$. falciparum mono infection, had no history of antimalarial drug use in the previous 14 days, were inpatients for minimum 7 days, and their parents gave informed consent. Exclusion criteria was one of the following conditions: one or more general danger signs or any sign of severe and complicated malaria, the presence of severe disease, severe malnutrition, fever caused by other diseases such as dengue fever, typhoid fever, pneumonia, etc., and history of hypersensitivity reactions to sulfonamides. Patients were recruited from the outpatient pediatric clinic and pediatric emergency room at MCGH. The Ethics Committee of the MCGH approved the study.

\section{Procedures}

The patients were randomly allocated (using a table of random numbers) to one of the two treatment groups, chloroquine-and-PS or artemether-and-PS. Thirty eligible children received chloroquine (10 $\mathrm{mg} / \mathrm{kg}$ for 2 days, then $5 \mathrm{mg} / \mathrm{kg}$ in the $3^{\text {rd }}$ day) and PS (pyrimethamine 1-1.5 $\mathrm{mg} / \mathrm{kg}$ single dose on the $1^{\text {st }}$ day) and 30 children were treated with artemether (4 mg/kg over 3 days) and PS.

A physician administered all of the drugs orally and each child was observed for at least 30 minutes after each supervised drug treatment in order to ensure that the drug was not vomited. The two groups received either only mechanical antipyretics or in combination with paracetamol, if the body temperature was $>38^{\circ} \mathrm{C}$. Clinical observations were recorded daily for 8 days (day 0 to 7 ). At each followup, the parents (and when possible, the children) was actively questioned using a questionnaire, and the children were examined for the presence of adverse reactions to drugs. Before treatment we did a full blood count, including hemoglobin, platelets, and differential count. Body temperature was recorded every 8 hours with electronic thermometers to one decimal point for 8 days (day 0 to 7 ). We also recorded the pulse rate, respiratory rate, and blood pressure. Thick blood smears, for quantification of parasitemia, were prepared every morning for 8 days (day 0 to 7).

Parasite clearance time was the time from the start of treatment until the first time the slide was negative at three-time examinations. A temperature of $\geq 37.5^{\circ} \mathrm{C}$ was judged as fever. Fever clearance time was the time from the start of treatment until the temperature measured was below $37.5^{\circ} \mathrm{C}$ and did not rise to $>37.5^{\circ} \mathrm{C}$ for minimum 72 hours. Cure rate was defined as absence of fever and parasitemia on day 7. A dropped out patient was defined as a patient lost to follow-up despite fulfilling all inclusion criteria without developing any exclusion criteria during the follow-up period.

\section{Laboratory methods}

Preparation and staining of the blood slides followed the procedures outlined in Basic Malaria Microscopy 1 (WHO, 1991). ${ }^{6}$ Thick blood films were stained with Giemsa. Parasite density was measured as the number of parasites per 200 white blood cells (WBC) 


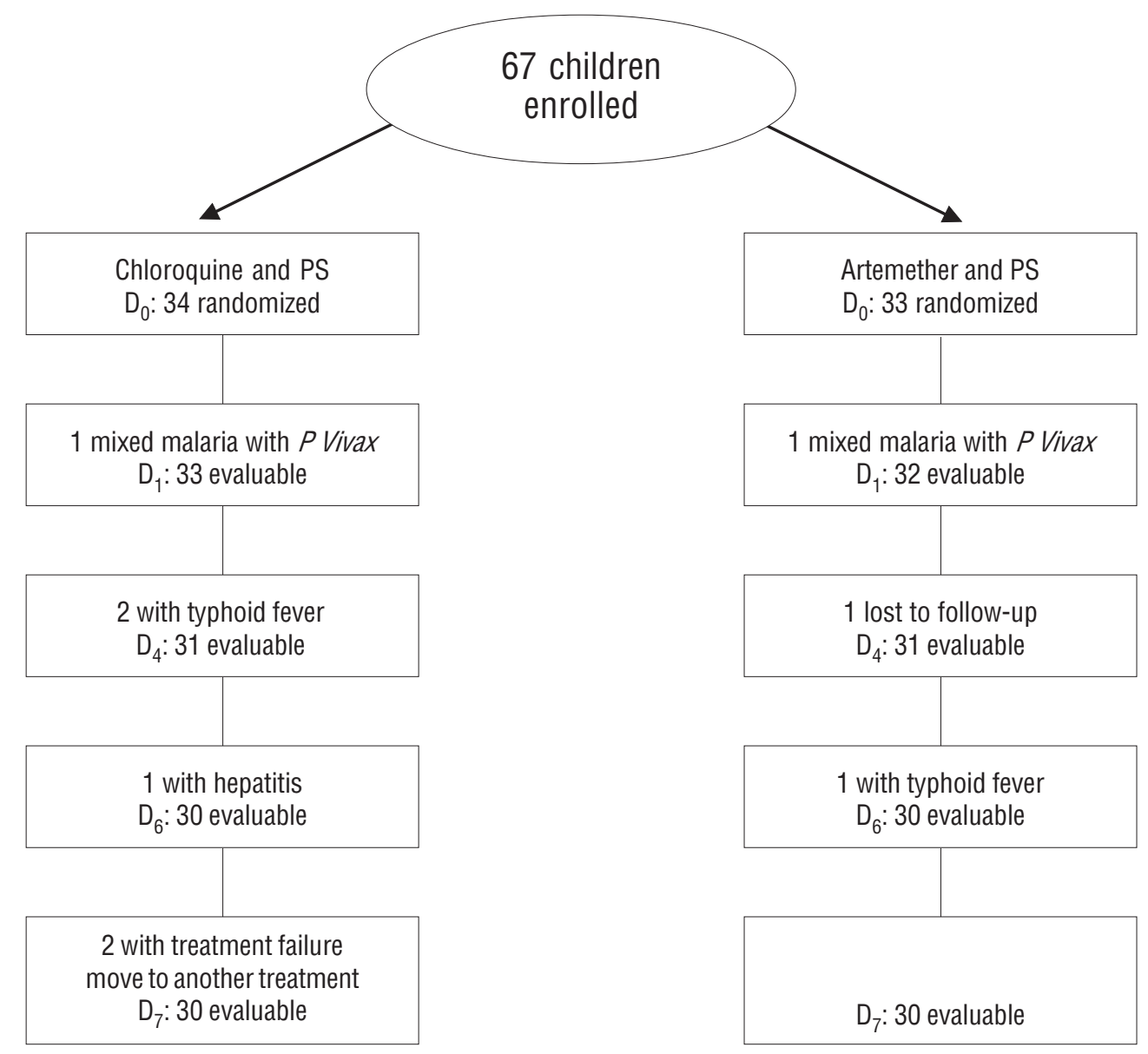

Figure 1. FloW CHART OF THE CHILDREN, INDICATING THEIR DISPOSITION FOLLOWING ENROLLMENT INTO THE STUDY

Table 1. Characteristics of ChildRen treated With CHLOROQUINE AND PS OR ARTEMETHER AND PS AT THE TIME OF ENROLLMENT

\begin{tabular}{lcc}
\hline Characteristics & $\begin{array}{c}\text { Chloroquine } \\
\text { and PS }\end{array}$ & $\begin{array}{c}\text { Artemether } \\
\text { and PS }\end{array}$ \\
\hline Patients enrolled & 30 & 30 \\
Males/Females & $12 / 18$ & $18 / 12$ \\
Median age in years/SD & $6.8 / 3.5$ & $5.8 / 3.3$ \\
Median weight in kg/SD & $20.7 / 9.3$ & $17.3 / 6.6$ \\
Hepatomegaly & 24 & 24 \\
Splenomegaly & 20 & 19 \\
Median Hb/SD (g/dL) & $10.3 / 1.95$ & $10.2 / 1.74$ \\
Median temperature at & $38.7^{\circ} \mathrm{C}$ & $38.7^{\circ} \mathrm{C}$ \\
baseline & & \\
Median number of & & \\
parasite at baseline/SD & $402.8 / 854.67$ & $558.1 / 1,111.28$ \\
$\left(\mathrm{~mm}^{3}\right)$ & & \\
\hline
\end{tabular}

on a thick film, assuming a total WBC count of $8.0 \times 10^{9} / \mathrm{L}$. If gametocytes were seen, the gametocyte count was extended to 1000 WBC. Experienced parasitologist read all of the slides.

Statistical analysis. Normally distributed data were compared using the Student's $t$-test; homogeneity of variance was tested by the F-test. Discrete data were compared by Fischer's exact test.

\section{Results}

Patients' characteristics. A total of 83 children who presented with malaria (fever and positive blood smear) at the trial site were screened between March and September 2002. Sixty-seven eligible children could be enrolled but 7 patients 


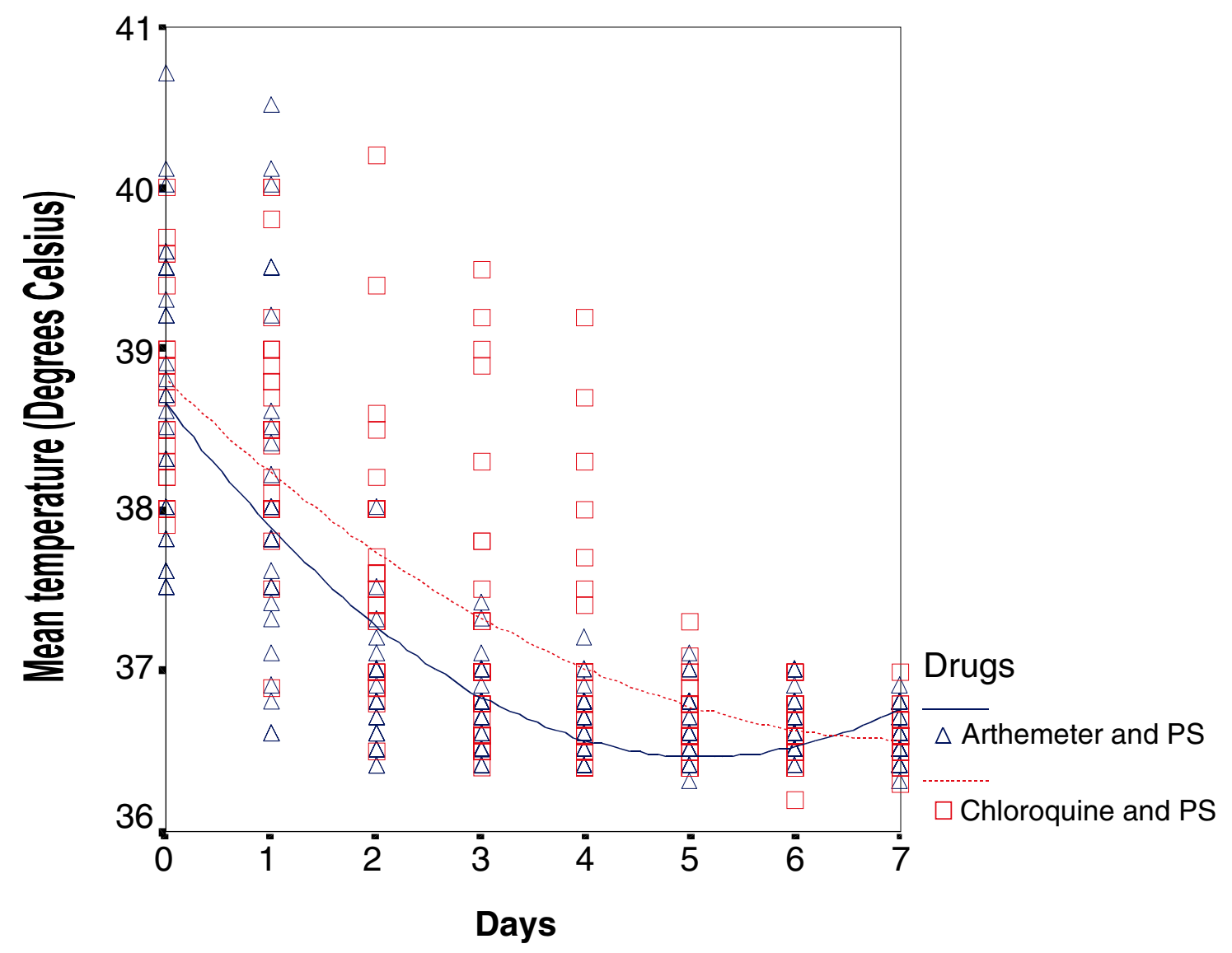

Figure 2. FeVER Reduction in malaria Patients treated With CHLOROQuine and PS Compared With ARTEMETHER AND PS (42 HR FOR ARTEMETHER AND PS, 75 HR 50 MINUTES FOR CHLOROQUINE AND PS)

were dropped out, two suffered from mixed malaria during follow-up, four suffered from malaria combined with other infectious disease such as typhoid fever and hepatitis A, and one patient failed to complete the treatment due to withdrawal of consent (Figure 1).

Both of the two groups were similar in gender, age, weight, and baseline clinical features (Table 1). Fever clearance time was significantly shorter in the group treated with artemether and PS than that in the group that received chloroquine and PS (Figure 2). In the artemether-and-PS group, normal temperature was achieved in 42 hours (SD 12 hours 59 minutes), while in the chloroquine-andPS group, it was 75 hours 50 minutes (SD 30 hours 6 minutes), $\mathrm{p}<0.001$. Hundred percents of children were febrile at enrollment. On day 3, only 1 patient had fever in the artemether-and-PS group, and on day 4 there was no patient who had fever. In the chloroquine-and-PS group, on day 3 there were still 7 patients who had fever but on day 5 , no patient had fever (data not shown).

Parasite clearance time was significantly different in the group that received artemether and PS compared with that of the chloroquine-and-PS group (2.5 days/SD 0.97 days vs. 3.1 days/SD 1.02 days, $\mathrm{p}=0.04$ ) (Figure 3). On day 3 , four children treated with artemether and PS and 6 children treated with chloroquine and PS still had parasitemia as shown in their blood smears. On day 5, all children treated with artemether and PS who could be evaluated had their parasites cleared in contrast with 2 chloroquine-and-PS-treated children who still had parasitemia (data not shown).

The cure rate of the chloroquine-and-PS group was 28/30, 2 children still showed para- 


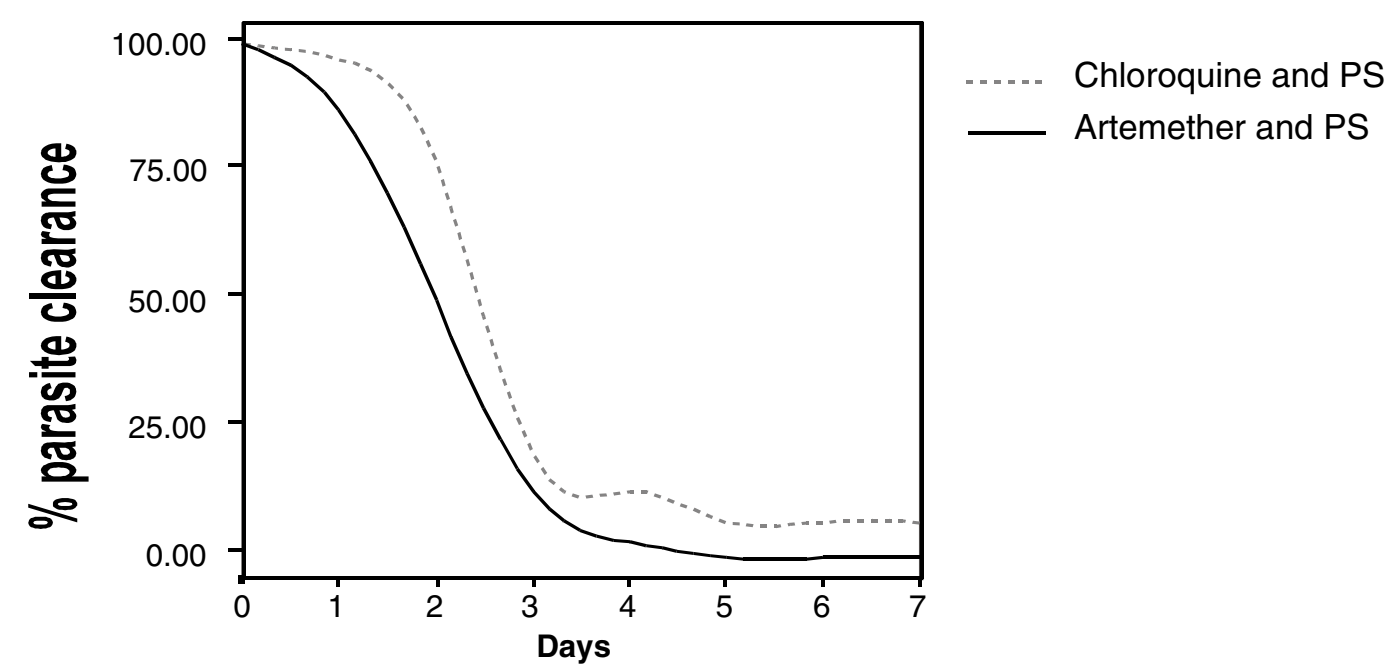

Figure 3. Parasitologic response of falciparum malaria to chloroquine and PS compared WITH ARTEMETHER AND PS, AS SHOWN BY PARASITE DENSITY CLEARANCE TIME

sitemia until day 7 (Table 2) although they did not have fever or showed resistance (R). Both of them got alternative treatment for drug failure, quinine $10 \mathrm{mg} / \mathrm{kg}$ orally 3 times daily for 7 days. One patient was clear from parasite on day 9 and the other on day 10 . No serious adverse reaction was attributable during 7 days of treatment. One patient of the chloroquine-and-PS group had nausea and vomiting on day 0 to 1 , after 8 hours of treatment, but disappeared on day 2 .

TABle 2. Cure rate In the two groups of treatment

\begin{tabular}{lcc}
\hline & $\begin{array}{c}\text { Chloroquine and } \\
\text { PS group }(\mathbf{n}=\mathbf{3 0})\end{array}$ & $\begin{array}{c}\text { Artemether and } \\
\text { PS group }(\mathbf{n}=\mathbf{3 0})\end{array}$ \\
\hline Cure by $7^{\text {th }}$ day & 28 & 30 \\
No cure by $7^{\text {th }}$ day & 2 & 0 \\
\hline Fischer exact test $p=0.2458$ & &
\end{tabular}

\section{Discussion}

Malaria parasites acquire resistance to antimalarial drugs due to mutation. Rapid parasite clearance may, therefore, lower the chance of drug-resistant strains emerging. Artemisin derivatives are the most potent and short-acting antimalarial drugs. The combination of a short-acting artemisin derivative with a longer-acting drug, such as PS, has the advantage that any parasites remaining after the artemisin derivative has worked are eliminated by a drug with different mode of action, therefore, emergence of resistance to each drug is less likely. ${ }^{12}$ To our knowledge, this was the first study evaluating the efficacy of artemether and PS compared with chloroquine and PS in our region.

Fever is the manifestation of malaria that most frequently causes discomfort. ${ }^{13}$ Thus, it was encouraging that children treated with artemether and PS became afebrile significantly faster than those treated with chloroquine and PS. Sleiden et al ${ }^{14}$ have compared artemether to PS monotherapy and found that the use of antipyretics was lower with artemether (significant in day 2 and 3; p <0.01). Another study in Gambia showed that the combination of artesunate and PS was more faster in lowering the body temperature in day $1, p=0.01 .^{8}$

Parasite clearance time in our results is parallel with those of other studies. ${ }^{8,14,15}$ In our study, there was no side effect found in the artemether group. Looareesuwan et al found itching and fine macular rash in 3 patients treated with artesunate (derivative artemisin). The itching was mild and the rash was present only on the extremities. These symptoms were present from day 2, but did not require any treatment. Another study with artesunate suppository showed that 1 child developed hyperpyrexia (oral temperature of $43.0^{\circ} \mathrm{C}$ ) in 8 hours after the first suppository. ${ }^{15}$ 
Femmy Tambajong et al: Artemether and pyrimethamine sulfadoxine in falciparum malaria treatment

Our study showed that artemether and PS combination was well tolerated and the cure rate was 30/ 30. It might be due to the fact that artemether is a new drug with limited users in this area. There is widespread concern that uncontrolled use of oral formulations of artemisin and its derivatives can lead to rapid decline in their efficacy. In order to maintain their powerful antimalarial activity, the use of artemisin and its derivatives should be primarily restricted. However, in areas such as those in South East Asia, the use of oral formulations to treat uncomplicated falciparum malaria is also indicated. ${ }^{16}$

We concluded that the combined treatment of artemether and PS was well tolerated in our subjects and no adverse reactions attributable to the treatment were noted. Despite this result, we still need more study in other regions with different populations and especially for evaluation in more than 7 days (extended until 28 days) because parasite clearance reflects factors other than treatment type, including preexisting immunity, the initial parasitemia, and clinical severity.

\section{References}

1. Departemen Kesehatan Republik Indonesia. Direktorat Jendral Pemberantasan Penyakit Menular dan Penyehatan Lingkungan Pemukiman. Buku saku penatalaksanaan kasus malaria. Jakarta: 2000.

2. Rampengan TH, Rampengan J. Chloroquine resistant falciparum malaria in children. Pediatr Indones 1989;29:13-9.

3. Rampengan J, Rampengan TH. Malaria tropika pada anak yang resisten II terhadap fansidar. MKI 1988;38:77-80.

4. Wilairatana P, Krudsood S, Treeprasertsuk S, Chalermrut K, Looareesuwan S. The future outlook of antimalarial drugs and recent work on the treatment of malaria. Arch of Med Research 2002;33:416-21

5. Budijanto SK. Artemisin: senyawa baru antimalaria. JDKI 1994;2:39-41.

6. WHO. Assesment of therapic efficacy of antimalarial drugs for uncomplicated falciparum malaria. Draft March 2001.
7. Looareesuwan S, Viravan C, Vabijanonta S, Wilairatana. Randomised trial of artsunate and mefloquine alone and in sequence for acute uncomplicated falciparum malaria. Lancet 1992;339:821-4.

8. Seidlein LV, Miligan P, Pinder M, Bojang K, Anyalebechi $\mathrm{C}$, Gosling $\mathrm{R}$ et al. Efficacy of artesunate plus pyrimethamine-sulphadoxine for uncomplicated malaria in Gambian children: a double-blind, randomized, controlled trial. Lancet 2000;355:352-7.

9. Vries PJ, Bich NN, Thien HV, Hung LN, Anh TK, Kager PA, et al. Combinations of artemisin and quinine for complicated falciparum malaria: efficacy and pharmacodynamics. Antimicrob Agents Chemother 2000;44:1302-8.

10. Tjitra E, Pribadi W, Raharjo K,Budiono W, Arbani PR, Naibaho et al. Treatment of uncomplicated in vitro chloroquine resistant falciparum malaria with artemether in Irian Jaya. Med J Indones 1996;5:33-41.

11. Madiyono B, Moeslichan S, Sastroasmoro S, Budiman I, Purwanto SH. Perkiraan besar sample. Sastroasmoro S, Ismael S, editor. Dasar-dasar metodologi penelitian klinis. 1st ed. Jakarta: Binarupa Aksara; 1995. p. 187-212.

12. White NJ. The treatment of malaria. N Eng J Med 1996;335:800-06.

13. Rampengan TH. Malaria pada anak. In: Harijanto PN, editor. Malaria: epidemiologi, patogenesis, manifestasi klinik, dan penanganan. $1^{\text {st }}$ ed. Jakarta: EGC; 2000. p. 49-75.

14. Seidlein LV, Bojang K, Jones P, Jaffar S et al. A randomized controlled trial of arthemeter benflumetol, a new antimalarial and pyrimethamine sulphadoxine in the treatment of uncomplicated falciparum malaria in Africa children. Am J Trop Med Hyg 1998;58:638-44.

15. Karunajeewa HA, Kemiki A, Alpers MP, Lorry K, Batty KT, Ilett KF, et al. Safety and therapeutic efficacy of artesunate suppositories for treatment of malaria in children in Papua New Guinea. Pediatr Infect Dis J 2003;22:251-5.

16. WHO, Division of Control of Tropical Disease. Management of uncomplicated malaria and the use of antimalarial drugs for the protection of travelers. Report of an Informal Concultion; Geneva; 1995 Sept $18-21$. 